\title{
Myths and facts in herbal medicines: Eleutherococcus senticosus (Siberian ginseng) and its contraindication in hypertensive patients
}

This article was published in the following Dove Press journal:

Botanics: Targets and Therapy

18 July 2014

Number of times this article has been viewed

\section{Mathias Schmidt ${ }^{1}$ \\ Michael Thomsen ${ }^{2}$ \\ Olaf Kelber ${ }^{3}$ \\ Karin $\mathrm{Kraft}^{4}$}

'Herbresearch Germany, Mattsies, Germany; ${ }^{2}$ Herbresearch Pty Ltd, South Hobart, Tasmania, Australia; ${ }^{3}$ Scientific Department, Steigerwald Arzneimittelwerk GmbH, Darmstadt, Germany; ${ }^{4}$ Universitätsmedizin Rostock, Rostock, Germany
Correspondence: Mathias Schmidt Herbresearch Germany,

Wartbergweg 15, Mattsies, Germany Tel +49 8268908174

Fax +498268908I75

Email schmidt@herbresearch.de
Background: Eleutherococcus senticosus radix (also known as "Siberian ginseng" or "eleuthero") is used as a medicinal plant in cases of asthenia with fatigue and weakness, a condition especially common in elderly patients. Most reviews and monographs state the contraindication "arterial hypertension". This excludes many elderly patients from therapy with eleuthero, as the prevalence of arterial hypertension in this age group is high. The origin and substantiation of this contraindication appears, however, unclear.

Methods: Available data on eleuthero in the context of hypertension was searched and evaluated systematically for an increase in blood pressure after application of corresponding preparations.

Results: Numerous clinical and preclinical studies with eleuthero, as well as reviews and monographs were identified. All sources directly or indirectly refer to only two Russian publications from 1966, presented to the Western world in a review in 1985. Later citations of these two Russian sources tended to mix up the results described therein, frequently indicating the observation of secured adverse effects in hypertensive patients. Such warnings are neither in accordance with the original data, nor are they supported by other published data, which rather point to potential antihypertensive effects.

Conclusion: The contraindication "arterial hypertension" is not evidence-based and should be carefully re-evaluated for not unnecessarily excluding a large patient group from the benefits of eleuthero.

Keywords: Eleutherococcus senticosus, Siberian ginseng, eleuthero, arterial hypertension, contraindication

\section{Introduction}

Eleutherococcus is a genus of 38 species of thorny shrubs and trees in the Araliaceae family. Eleutherococcus senticosus (Rupr et Maxim) Maxim (syn Acanthopanax senticosus) is a plant endemic to the Amur region in Siberia. The plant has been introduced into Western medicine as a consequence of the search by Russian scientists for a potential substitute for ginseng (Panax ginseng), a species from the same plant family (Araliaceae) well-known for its strengthening effects on the immune system. Intensive clinical research confirmed the appropriateness of a so-called "adaptogen", a remedy allowing the adaptation of the immune system to adverse conditions. ${ }^{1,2}$ Correspondingly, preparations of the root of eleuthero are given in cases of asthenia with weakness and fatigue, eg, in convalescence. This indication has been officially accepted by the "Community Herbal Monograph on Eleutherococcus senticosus (Rupr et Maxim) Maxim Radix" (EMEA/HMPC/244569/2006), published by the European 
Medicines Agency. The positive effects on vigor and immune capacity were also exhaustively examined in reviews. ${ }^{3-6}$

The clinical application of eleuthero is generally considered safe. However, the European Community Herbal Monograph states "arterial hypertension" as a contraindication. The same restriction is also found in many monographs, reviews, ${ }^{1,4-9}$ and online databases (eg, http:// naturaldatabase.therapeuticresearch.com). The intention of contraindications is the exclusion of patients from treatment, if there are specific concerns regarding clinical safety. In the case of eleuthero, the proportion of the excluded patients is likely to be high, as herbal medicinal products containing eleuthero are indicated "for symptoms of asthenia such as fatigue and weakness" - an indication especially common in senior patients, and the prevalence of arterial hypertension in patients $>65$ years has been stated to be $56 \%-59 \%{ }^{10}$

The contraindication "arterial hypertension" is therefore highly restrictive for the clinical use of eleuthero. The origin of the contraindication appears, however, somewhat elusive. We therefore traced the available evidence supporting the contraindication by means of literature retrieval and rigorous analysis of the original publications.

\section{Research design and methods}

A systematic database search was conducted in Embase and MEDLINE. Keywords were Eleutherococcus, Acanthopanax, Eleutherococci, or Siberian ginseng. The results were narrowed down by hand-searching. For all hits, the original publication was examined for mention of hypertension and for secondary citations. Statements mentioned in publications and reviews with reference to published sources were compared with the original data from the cited publication.

\section{Results}

\section{The monograph of Farnsworth et $\mathrm{al}^{2}$}

All references relating to the contraindication "hypertension" in reviews and monographs can be traced back to the review of Farnsworth et al, ${ }^{2}$ which contains an English compilation of the early Russian original research works on eleuthero, and therefore made Eleutherococcus research available to the Western world. ${ }^{2}$ The comparison of the statements of later publications with this review and with the original sources allows the conclusion that most references indirectly cite from the review (even if it is not quoted), but not from the source material.

The review of Farnsworth et $\mathrm{al}^{2}$ cites studies in 2,100 healthy subjects and 2,200 patients suffering from various diseases, including atherosclerosis, acute pyelonephritis, diabetes (several types), acute craniocerebral trauma, various types of neuroses (ambulatory and hospitalized patients were studied), rheumatic heart disease, chronic bronchitis, cancer, and last, but not least, hypertension and hypotension.

In all studies where the effect on blood pressure was examined, an improvement of hypertensive states was reported. This is in accordance with the results of a more recent doubleblind clinical trial, in which hypertension was even defined as an indication for treatment with eleuthero. ${ }^{11}$

There are only two original sources cited by Farnsworth et al and regularly - directly or indirectly - referenced to as proof of the contraindication in hypertension in all relevant monographs and reviews:

- Mikunis et $\mathrm{al}^{12}$ published a trial on 55 patients with rheumatic heart disease treated with a preparation of eleuthero.

They reported an increase in blood pressure in two of the exposed patients. Farnsworth et al described the study as follows: "Another study involving 55 patients with rheumatic heart disease (Mikunis et al 1966a), showed that 2 of the patients (at high dose levels of the extract) reported headaches, pericardial pain, palpitations and elevated blood pressure". ${ }^{12}$ Quite obviously, the "side effect" was not reproducible, as a second study of the same author with another 55 patients suffering from the same ailment did not lead to the observation of the alleged side effect. ${ }^{13}$

In view of the well-known spontaneous incidence of hypertension in patients suffering from rheumatic heart disease, causality by eleuthero cannot be considered convincingly established.

- A blood pressure of $180 / 90 \mathrm{mmHg}$ is frequently cited in publications on eleuthero. This figure occurs in the trial of Dalinger - but not in the context of an adverse effect. ${ }^{14}$ In fact, this study does not even report any observed adverse effects.

Dalinger $^{14}$ had examined 35 female workers doing physical work in a publishing house. Twenty-four of these study participants were hypertensive with systolic values in the range of 135-164 $\mathrm{mmHg}$. One woman had blood pressure values of $180 / 90 \mathrm{mmHg}$. These women received 25-30 drops of a fluid preparation of eleuthero (probably extracted with ethanol) twice daily for 12 consecutive days. The control group consisted of ten women who received vitamins. Improvement was noted in parameters of the cardiovascular system, ability to work, appetite, and general well-being, but clearly positive effects were restricted to "those without marked hypertension". Dalinger had observed an improvement 
of systolic blood pressure by an average of $12.4 \mathrm{mmHg}$ in hypertensive patients with baseline values between 135 and $164 \mathrm{mmHg}$.

Based on these observations, Dalinger proposed and recommended the use of eleuthero for subjects with blood pressure values below 180/90 $\mathrm{mmHg}$.

Thus, Dalinger did not state hypertension as a contraindication, but merely proposed a limitation of the clinical use to the range of patients he had treated successfully. With a blood pressure of $180 / 90 \mathrm{mmHg}$, the patients did not benefit from eleuthero exposure but were not harmed by it either. Dalinger's recommendation led to misinterpretations due to mistranslations of the relevant statements from the original paper, which was written in Russian. A major source of such misunderstandings is the summary of Dalinger's study in Biological Abstracts (BA 1966: 106799), stating (verbatim): "The extract is not recommended for administration in persons whose blood pressure is $180 / 90 \mathrm{mmHg}$ or higher". The Russian original, however, does not say "not recommended", it says "Нецелесообразно", which translates to "not useful". Citations and re-citations have therefore falsified a statement aimed on clinical usefulness into a statement supposedly aimed on safety of application.

A major source for a misunderstanding may be a small glitch in the references made in the review of Farnsworth et al. ${ }^{2}$ They summarize: "No side effects were reported in any of the studies [...]. However, in two of the studies, it was recommended that the extract should not be given to subjects having blood pressure in excess of 180/90 mmHg (Dalinger 1966b; Lapchik 1967)". Of note: in this place, Farnsworth et $\mathrm{al}^{2}$ refers to the study performed by Dalinger with the 35 female workers of a publishing house. Within the tabulated data, however, the reference points to another study of Dalinger performed in 76 skiers exposed to a single dose of eleuthero. ${ }^{15}$ This sports study does not show any reference to hypertension.

Whereas the reference of Farnsworth et al to Dalinger is technically correct (as long as it relates to the study in the female workers), the reference to Lapchik is not.

Due to the mention by Farnsworth et al, the publication by Lapchik is frequently referred to for the substantiation of adverse effects related to hypertension. However, this study was not even a clinical or pharmacological examination: Lapchik published data on the germination characteristics of radish seeds under the effect of eleuthero extract. ${ }^{16}$
Two further publications cited by Farnsworth et al are frequently mentioned as sources of adverse effect reports in the context of hypertension:

- Golikov is regularly cited as a source of case reports of hypertension related to the exposure to Eleutherococcus senticosus. For example, Farnsworth et $\mathrm{al}^{2}$ summarized: "In two studies involving atherosclerotic patients, some incidence of insomnia, shifts in heart rhythm, tachycardia, extrasystoles, and hypertonia was reported (PP Golikov, 1966a,b)." Both citations of Farnsworth et al refer to the same study, which was also published by the same authors in 1967, possibly adding to the confusion.

Golikov $^{17}$ and a third publication of Golikov cited by Farnsworth et $\mathrm{al}^{2}$ report the treatment of 64 patients with $1.5-2 \mathrm{~mL}$ three times a day of a liquid eleuthero preparation for 6-8 treatment cycles, each with a duration of 25-35 days. Of these patients, 45 suffered from atherosclerosis. Farnsworth et al provide clinical details and state the observations of Golikov with respect to adverse events: "Side effects observed with the use of $E$. senticosus extract, based on results in some patients, were insomnia, shifts in heart rhythm, tachycardia". At the end of the treatment "most patients had shown an improvement in general feelings and condition; pains in the heart and chest had disappeared; blood pressure was reduced". ${ }^{17}$ The citation referenced to by Farnsworth et al as "Golikov 1966b" could not be retrieved, but in any case, hypertonia was not observed. ${ }^{2}$

Golikov $^{2}$ observed a reduction in serum prothrombin and cholesterol levels; and electroencephalography data were improved. (The latter citation was found in Farnsworth et al). ${ }^{2}$ The authors state that "Treatment was less effective in patients with high blood pressure or functional disorders of the central nervous system. Eleutherococcus senticosus extract was well tolerated by the patients." There were no adverse effects reported, especially not one related to hypertension; however, the authors merely observed that patients with higher blood pressure levels do not respond as well to eleuthero treatment as do patients with less severe hypertension. Unfortunately, it was not possible to retrieve the original article with the citation given by Farnsworth et al.

- Koshkareva and Kovinskii18 ${ }^{18}$ have been cited as a source of case reports of adverse events, including hypertension. The authors treated eleven hypochondriac patients for 60 days. Adverse events noted in this observational trial were "insomnia, irritability, melancholy and anxiety in some patients. Doses of $2.5-3.0 \mathrm{~mL}$ were optimal (minimal side effects), and doses of $4.5-6.0 \mathrm{~mL}$ seemed 
to cause most of the side effects." ${ }^{18}$ The authors do not mention hypertension as an adverse event.

Farnsworth at al tabulated this study with a reference to "some" patients with adverse events, adding in the main text that "patients often showed" these adverse events. This latter interpretation is misleading without a reference to the dose-effect relationship, but in any case, there was no mention of hypertension.

Other studies reviewed by Farnsworth et al included patients with hypertension, and the exposure to eleuthero led to improvements of blood pressure. ${ }^{19-21}$ More recent trials published after the appearance of the review of Farnsworth et $\mathrm{al}^{2}$ never observed hypertensive reactions as a consequence of eleuthero exposure $^{11,22-28}$ - some results rather exhibited an effect against unwanted elevations of blood pressure. ${ }^{29}$

\section{Other monographs and reviews}

Hypertension as a contraindication or even an adverse effect is frequently mentioned in monographs on eleuthero. A closer examination of the sources for this information always results in a regression to the review of Farnsworth et al, ${ }^{2}$ and misleading re-interpretations of the source material. . $^{1,4,5,8,30,31}$ In some monographs and reviews, the information on hypertension as a contraindication can be indirectly traced back to Farnsworth et $\mathrm{al}^{2}$ via the monograph of the German Commission $E^{8,9,31-34}$ and/or the World Health Organization monograph. ${ }^{7}$

A recent and striking example of misleading information is the monograph "Ginseng, Siberian" of the Natural Medicines Comprehensive Database, available online for subscribers (http://naturaldatabase.therapeuticresearch.com; downloaded version last updated in 2012). According to the "Adverse Reactions" section, "Siberian ginseng should be used cautiously in patients with cardiovascular disorders (eg, atherosclerotic or rheumatic heart disease), because it can cause palpitations, tachycardia, and hypertension". As a source, the monograph refers to the book "Mills S, Bone K, Principles and Practice of Phytotherapy. London: Churchill Livingstone, 2000", which could not be checked for citations. However, the same authors later published the book The essential guide to herbal safety in 2005, which does not justify the contraindication or the adverse effect with corresponding sources of information. ${ }^{8}$

The contraindication is again repeated with the same citation in the section on "Interactions with diseases or conditions - Cardiovascular conditions". In the specific subsection "Hypertension", the monograph states that: "Siberian ginseng is contraindicated in individuals with blood pressure exceeding 180/90. Siberian ginseng can potentially exacerbate hypertension" - in this case, the reference is the AHPA's Botanical Safety Handbook in its issue of $1997,{ }^{35}$ and thus again to a source not giving justification for the rather drastically written warnings.

\section{Eleuthero and hypertension in pharmacovigilance}

Jacobsson et al $^{36}$ analyzed data of adverse events reports by the Swedish regulatory database. Seven hundred and seventy-eight out of a total of 64,493 reports filed in the period 1987-2006 were related to complementary and alternative medicines (CAM). The authors examined these case reports for symptoms and frequencies, independent of the causality assessment. Consequently, the data presented in this publication are based on the clearly erroneous assumption of causality in every single filed report. Eleuthero is mentioned as a frequently reported plant $(n=57 ; 7.3 \%$ of all CAM reports); however, not as a single active constituent, but in combination with Echinacea and Adhatoda vasica. The reported adverse events were urticaria $(n=16)$, angioedema $(n=14)$, anaphylactic reactions $(n=7)$, exanthema $(n=5)$, elevated liver function tests $(n=2)$, fever $(n=2)$, and others $(n=11)$. Effects on blood pressure were not filed for any of the listed herbal preparations. ${ }^{36}$

Rasmussen et $\mathrm{al}^{37}$ start with the assumption that patients suffering from hypertension would frequently take natural remedies in addition to or even instead of the prescribed medication. The authors identify this entirely hypothetical situation as a risk. As an example, the authors claim that eleuthero (next to Ephedra, bitter orange, and liquorice) is "consistently associated with increasing blood pressure". ${ }^{37}$ The authors admit that Siberian ginseng is traditionally used for the regulation of blood pressure; however, "caution is advised because it has been documented to cause hypertension, tachycardia, and palpitations". In proof, the authors refer to the Natural Medicines Comprehensive Database, which does not, however, deliver any reproducible evidence for such a "consistent" observation.

\section{Discussion}

With eleuthero being administered for the strengthening of the immune system in convalescent patients and in times of stress, elderly patients belong to the main target population potentially profiting from the application of preparations of eleuthero root. Elderly subjects would, however, also frequently be affected by hypertension, and thus be excluded from potential benefits of eleuthero through a contraindica- 
tion consistently mentioned in practically all monographs and reviews. The analysis of the original sources of information cast doubt on this contraindication. It has been confirmed that the mention of hypertension as an adverse event was found in only two study participants out of a total of 4,300 tabulated by Farnsworth et al. These two patients participated in a study on eleuthero effects against rheumatic heart disease, where hypertension is part of the symptom complex.

Two of the studies cited in Farnsworth et $\mathrm{al}^{2}$ are regularly confused: Mikunis et al $^{12}$ did not mention a blood pressure of 180/90 $\mathrm{mmHg}$, and Dalinger ${ }^{14}$ did not observe hypertension as an adverse effect. Thus, citations regularly erroneously give the impression that an increase of blood pressure of 180/90 $\mathrm{mmHg}$ was observed as a consequence of eleuthero intake. ${ }^{4}$ Mikunis et al, ${ }^{12}$ the source for the only two reports on hypertension - in patients where hypertension is part of the underlying disease - reported nothing of the sort. In contrast, a statement of Dalinger referring to an assessment of efficacy in patients with very high blood pressure has somehow been connected to the observation of Mikunis et al, although both findings were completely unrelated in content and meaning.

Adverse events of eleuthero involving hypertension have not been reported in clinical studies, and do not seem to appear in pharmacovigilance databases. Some riskrelated publications merely speculate on adverse effects or hypertension-related contraindications, without providing reproducible or verifiable sources. The retrieval of the original sources demonstrate an overly alarmist quality to such statements, as they are not based on facts.

It should finally be mentioned that the original Russian sources speak of stage III hypertension, ${ }^{38}$ which today would correspond to a hypertensive crisis with manifest organ damage. Self-medication with any herbal medicinal product would in such cases clearly not be the treatment of choice, regardless of a contraindication.

\section{Conclusion}

According to the published knowledge and the available pharmacovigilance information the contraindication "arterial hypertension" for eleuthero is not evidence-based. There is no scientific base for the exclusion of hypertensive patients from the potential benefits of eleuthero.

\section{Authors' contributions}

All authors contributed toward data analysis, drafting and revising the paper and agree to be accountable for all aspects of the work. MS and MT did the bibliographic search and analysis. KK did the medicinal assessment of the observations described in the literature. OK contributed to the translation of the original Russian language sources of bibliography, and to the retrieval of copies of the original literature.

\section{Disclosure}

MS, MT, and KK declare that they have no conflict of interests. $\mathrm{OK}$ is working as a scientist for a pharmaceutical company, but not one marketing a product with eleuthero. There was no interference with the outcome of the literature analysis from the employer.

\section{References}

1. Baldwin CA, Anderson LA, Phillipson JD. What pharmacists should know about ginseng. Pharm J. 1986;236:583-586.

2. Farnsworth NR, Kinghorn AD, Soejarto DD, Waller DP. Siberian ginseng (Eleuterococcus senticosus): Current status as an adaptogen In: Wagner H, Hikino H, Farnsworth NR, editors. Economic and Medicinal Plant Research. London, Orlando, San Diego, New York, Toronto, Montreal, Sydney, Tokyo: Academic Press; 1985;(1): $155-215$.

3. ESCOP. Eleutherococci Radix. Eleutherococcus. In: Phytotherapy ESCo, editor. ESCOP Monographs. The Scientific Foundation for Herbal Medicinal Products. Stuttgart, Germany: Thieme-Verlag; 2009: $110-120$.

4. Anon. Siberian Ginseng. In: Mahady GB, Fong HS, Farnsworth NR, editors. Botanical Dietary Supplements: Quality, Safety and Efficacy. Lisse, The Netherlands: Swets and Zeitlinger Publishers; 2001:225-232.

5. Anon. Ginseng, Eleutherococcus. In: Barnes J, Anderson LA, Philipson JD, editors. Herbal Medicines (Electronic Version). London, UK: Royal Pharmaceutical Society, Pharmaceutical Press; 2007.

6. Radix Eleutherococci. WHO Monographs on Selected Medicinal Plants. Geneva, Switzerland: World Health Organization; 2002;(1): 83-96.

7. Anon. Eleutherococcus senticosus (Rupr and Maxim) Maxim, Araliaceae. In: Gardner Z, McGuffin M, editors. American Herbal Association's Botanical Safety Handbook. 2nd ed. Boca Raton, FL: CRC Press; 2013:329-331.

8. Anon. Siberian Ginseng. In: Mills S, Bone K, editors. The Essential Guide to Herbal Safety. St Louis, MO: Elsevier Churchill Livingstone; 2005:578-580.

9. Monographie: Eleutherococci radix (Eleutherococcus senticosusWurzel). BAnz. 1991(11):17.01.

10. Yankovskaya L. Prevalance of arterial hypertension and obesity among elderly people in Belarus and their quality of life. J Hypertens. 2010;28:e334

11. Cicero AF, Derosa G, Brillante R, Bernardi R, Nascetti S, Gaddi A. Effects of Siberian ginseng (Eleutherococcus senticosus maxim) on elderly quality of life: a randomized clinical trial. Arch Gerontol Geriatr Suppl. 2004(9):69-73.

12. Mikunis RI, Serkova VK, Shirkova TA. [Influence of Eleutherococcus on the immunobiologic reactivity of patients with rheumatic defects of the heart]. Lek Sredstva Dalônego Vostoka. 1966;7:221-226. Russian.

13. Mikunis RI, Serkova VK, Shirkova TA. [The effect of Eleutherococcus on some biochemical parameters of the blood in the combined treatment of patients with rheumatic lesions of the heart]. Lek Sredstva DalÔnego Vostoka. 1966;7:227-230. Russian.

14. Dalinger OI. [The effect of an extract of Eleutherococcus on the cardiovascular system and some measures of the ability to work of older persons]. [Central Nervous System Stimulants]. Tomsk, Russia: Toms University; 1966:112-114. Russian. 
15. Dalinger OI. [The action of an extract of Eleutherococcus on the condition of the cardiovascular system and the physical capability of skiers]. [Central Nervous System Stimulants]. Tomsk, Russia: Toms University; 1966:106-111. Russian.

16. Lapchik VF. [The action of biologically active substances of Elutherococcus senticosus on the plant organism]. Visn Kyyiv Univ Ser Biol. 1967;9:131-134. Russian.

17. Golikov PP. [Treatment of patients with atherosclerosis with the extract from Eleutherococcus]. Velmo Med Zh. 1966(9):24-27. Russian.

18. Koshkareva KI, Kovinskii KP. [The use of extract of Eleutherococcus senticosus in hypochondria]. [Central Nervous System Stimulants]. Tomsk, Russia: Tomsk University; 1966:128-130. Russian.

19. Mishchenko ED. Treatment of Diabetes mellitus patients with a liquid extract of Eleutherococcus roots. Simpoziumy po Eleuterokokku $i$ Zhen'shenyu, XX Sessiya Kom. po Izuch. Zhen'shenya i Drugikh Lekarstv. Rast. Dal'n. Vost. (CA: 59:14483f). Vladivostok1962:54.

20. Lyubomudrov VE, Basamygina LY, Bikezina VG, et al. [On the therapeutic efficacy of Eleutherococcus]. Vrach.Delo. 1970(1):102-105. Russian.

21. Galanova BK. [Eleutherococcus in the prophylaxis of influenza and relapses of essential hypertension]. Adaptation and Adaptogens. Vladivostok: Academy of Science of the USSR Far East Science Centre; 1977:126-127. Russian.

22. HartzAJ, Bentler S, Noyes R, et al. Randomized controlled trial of Siberian ginseng for chronic fatigue. Psychol Med. 2004;34(1):51-61.

23. Arushanian EB, Mastiagina OA. [Different effect of eleuterococcus on various psychophysiological parameters of healthy humans depending on their chronotype and the day time]. Eksperimental'naia i Klinicheskaia Farmakologiia. 2009;72(3):10-12. Russian.

24. Park SH, Kim SK, Shin IH, Kim HG, Choe JY. Effects of AIF on Knee Osteoarthritis Patients: Double-blind, Randomized Placebo-controlled Study. Korean J Physiol Pharmacol. 2009;13(1):33-37.

25. Schutgens FW, Neogi P, van Wijk EP, van Wijk R, Wikman G, Wiegant FA. The influence of adaptogens on ultraweak biophoton emission: a pilot-experiment. Phytother Res. 2009;23(8):1103-1108.

26. Aslanyan G, Amroyan E, Gabrielyan E, Nylander M, Wikman G, Panossian A. Double-blind, placebo-controlled, randomised study of single dose effects of ADAPT-232 on cognitive functions. Phytomedicine. 2010;17(7):494-499.

27. Bocharov EV, Ivanova-Smolenskaya IA, Poleshchuk VV, Kucheryanu VG, Il'enko VA, Bocharova OA. Therapeutic efficacy of the neuroprotective plant adaptogen in neurodegenerative disease (Parkinson's disease as an example). Bull Exp Biol Med. 2010;149(6):682-684.
28. Kuo J, Chen KW, Cheng IS, Tsai PH, LuYJ, Lee NY. The effect of eight weeks of supplementation with Eleutherococcus senticosus on endurance capacity and metabolism in human. Chin J Physiol. 2010;53(2): 105-111.

29. Facchinetti F, Neri I, Tarabusi M. Eleutherococcus senticosus reduces cardiovascular stress response in healthy subjects: a randomized, placebo-controlled trial. Stress Health. 2002;18:11-17.

30. Anon. Eleutherococci radix. Eleutherococcus. In: Phytotherapy ESCo, editor. E/S/C/O/P Monographs. The Scientific Foundation for Herbal Medicinal Products. Vol Supplement 2009. Stuttgart, New York: GeorgThieme-Verlag; 2009:110-120.

31. Aicher B, Wozniewski T. Eleutherococcus. In: Blaschek W, Ebel S, Hackenthal E, et al, editors. HagerROM 2006: Hagers Handbuch der Drogen und Arzneistoffe. Heidelberg, Germany: Springer Elektronische Medien; 2006. German.

32. Duke JA, Bogenschutz-Godwin MJ, duCellier P-A. Siberian Ginseng (Eleutherococcus senticosus (Rupr and Maxim) Maxim). Handbook of Medicinal Herbs. 2nd ed. Boca Raton, FL: CRC Press; 2002: 669-671.

33. Pakalns D, Kalke D. Assessment Report for Herbal Substances, Herbal Preparations or Combinations thereof with Traditional Use. Eleutherococcus senticosus (Rupr et Maxim) Maxim, Radix. London, UK: EMEA; 2008.

34. Bleakney TL. Deconstructing an adaptogen: Eleutherococcus senticosus. Holist Nurs Pract. 2008;22(4):220-224.

35. Anon. Eleutherococcus senticosus (Rupr ex Maxim) Maxim Araliaceae. In: McGuffin M, Hobbs C, Upton R, Goldberg A, editors. Botanial Safety Handbook. Boca Raton, FL: CRC Press; 1997:45.

36. Jacobsson I, Jonsson AK, Gerden B, Hagg S. Spontaneously reported adverse reactions in association with complementary and alternative medicine substances in Sweden. Pharmacoepidemiol Drug Saf. 2009;18(11):1039-1047.

37. Rasmussen CB, Glisson JK, Minor DS. Dietary supplements and hypertension: potential benefits and precautions. J Clin Hypertens (Greenwich). 2012;14(7):467-471.

38. Brekhman II. Eleutherococcus - ein wirksames und unschädliches Stärkungsmittel [Eleutherococcus - an efficacious and safe tonic]. Ostwestkonsum. 1974(11):58-60. German.
Botanics: Targets and Therapy

\section{Publish your work in this journal}

Botanics: Targets and Therapy is an international, peer-reviewed, open access journal focusing on the discovery and development of active compounds based upon or found naturally occurring in the plant kingdom that may have therapeutic potential in any disease state. The manuscript management system is completely online and includes a very

Submit your manuscript here: http://www.dovepress.com/botanics-targets-and-therapy-journal

\section{Dovepress}

quick and fair peer-review system. Visit http://www.dovepress.com/ testimonials.php to read real quotes from published authors. 